\title{
Surface plasmon resonance of layer-by-layer gold nanoparticles induced photoelectric current in environmentally-friendly plasmon-sensitized solar cell
}

\author{
Yen-Hsun $\mathrm{Su}^{1,2}$, Yuan-Feng Ke ${ }^{1}$, Shi-Liang $\mathrm{Cai}^{1}$ and Qian-Yu Yao ${ }^{1}$ \\ Layer-by-layer gold nanoparticles are used to generate photocurrent in an environmentally-friendly plasmon-sensitized solar cell towing \\ to surface plasmon resonance. The efficiency of the photoelectric conversion of gold nanoparticle layers is increased as the intensity of \\ surface plasmon resonance increases. We also explain the experimental results by modeling the phenomenon of charge separation and \\ photocurrent formation, and the relationship between surface plasmon resonance and photocurrent formation, which has potential \\ application in plasmon-sensitized solar cells and plasmonic solar cells in the future.
}

Light: Science \& Applications (2012) 1, e14; doi:10.1038/lsa.2012.14; published online 8 June 2012

Keywords: charge separation; layer-by-layer gold nanoparticles; plasmon-sensitized solar cells; plasmonic solar cells; surface plasmon resonance

\section{INTRODUCTION}

Nobel nanoparticles have many of the usual physical and optical properties, including surface plasmon resonance. ${ }^{1-6}$ Surface plasmon resonance produces a stronger electromagnetic field on the surface of gold nanoparticles and has been applied to the enhancement of Raman scattering, ${ }^{7}$ photoluminescence, ${ }^{8}$ biolight emission devices ${ }^{9}$ and solar cells. ${ }^{10}$

Recently, surface plasmon resonance of noble metals has been used to separate charges on $\mathrm{TiO}_{2}$ films to form negative potential changes and anodic currents under visible light radiation, ${ }^{3,11-14}$ which will potentially be able to facilitate the promising application of plasmon-sensitized solar cells and plasmonic solar cells in the future. A few studies ${ }^{3,11-14}$ have reported results concerning the phenomenon of plasmon-induced charge separation at $\mathrm{TiO}_{2}$ films loaded with gold nanoparticles. In these experiments, photons resulting from incident light couple with a plasmon to serve as an exciton to separate the charge on gold nanoparticles. The electron is then ejected from the gold nanoparticle onto $\mathrm{TiO}_{2}$ films. The photocurrents of $\mathrm{TiO}_{2}$ films loaded with gold nanoparticles were measured under visible light radiation. However, surface plasmon resonance is an electromagnetic standing wave. Few studies have reported how an electromagnetic standing wave, a frequency-dependent physical parameter, is able to produce a frequency-independent photocurrent (for frequencies of visible light ranging from $10^{14}$ to $10^{15} \mathrm{~Hz}$ ). By understanding the mechanism of surface plasmon resonance and optimizing the fabrication of a photocell, the efficiency of photovoltaic cells is able to be enhanced.
In this paper, we use gold nanoparticles loaded on $\mathrm{TiO}_{2}$ film to form photocurrents, as shown in Figure 1. Surface plasmon resonance is used to separate the charges on $\mathrm{TiO}_{2}$ films and form the photocurrent.

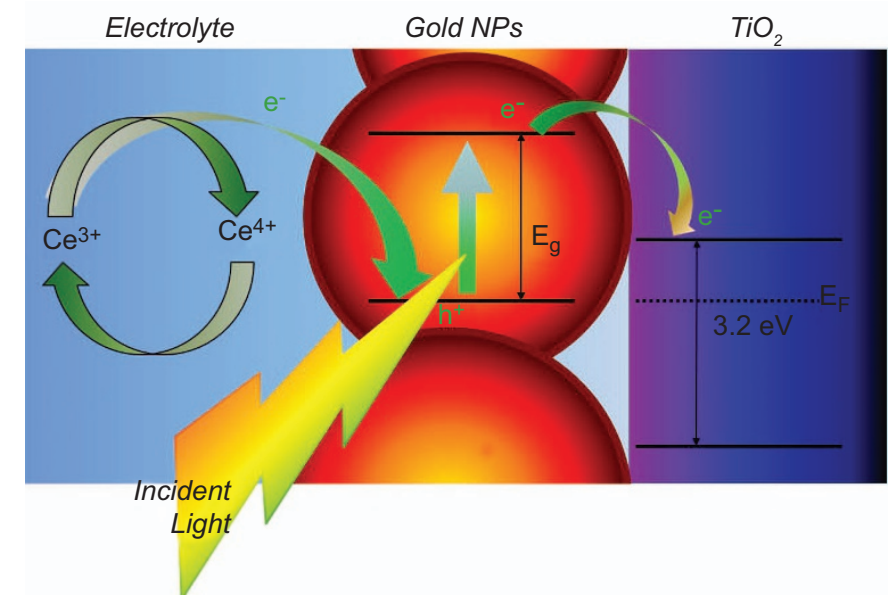

Figure 1 Scheme of plasmon-induced charge separation on gold nanoparticles in a solar cell. The SPR-induced dipole acts as an energy level. SPR enhances the pumping rate of the photoelectronic formation. The photoelectric current will rise. The chemical potential of electrolyte will change due to the external electric field of SPR. The open-circuit voltage is the difference between the conductive band of $\mathrm{TiO}_{2}$ and the chemical potential of the electrolyte. The open-circuit voltage will be shifted at the same time. Gold NPs, gold nanoparticles. 

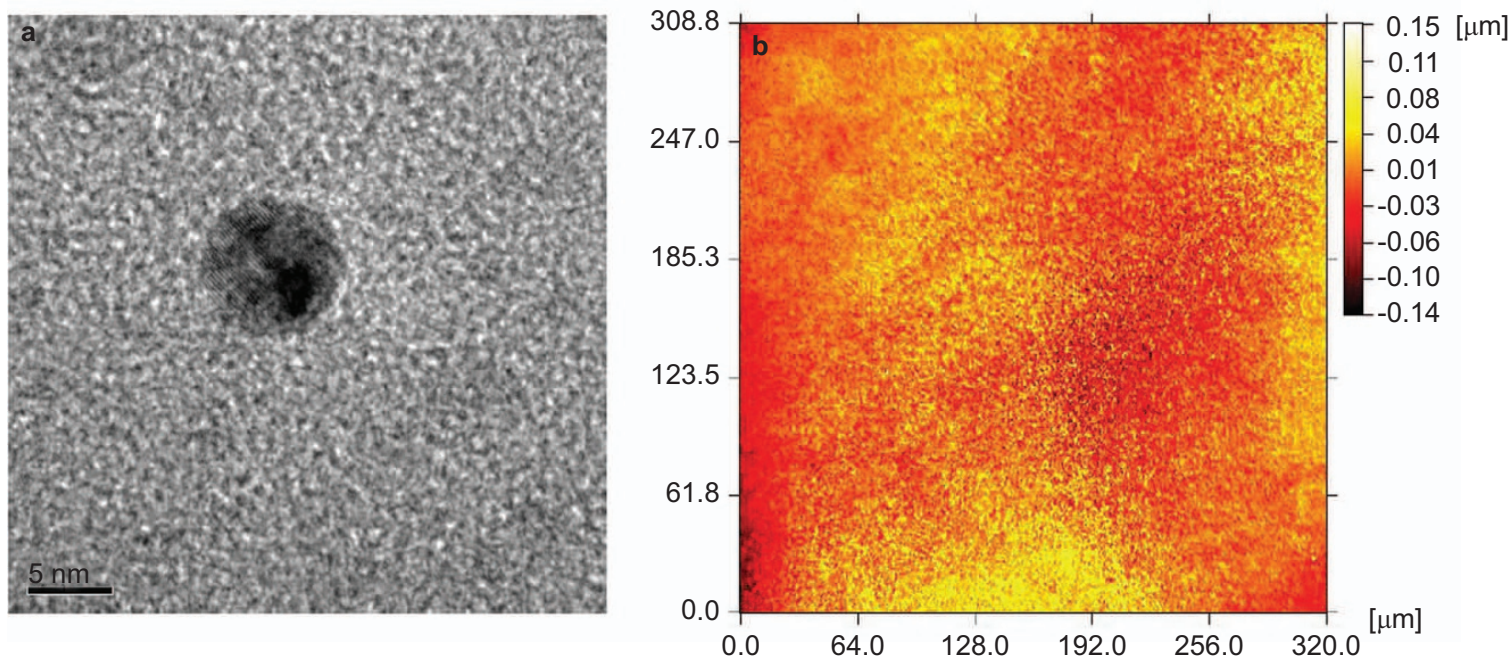

Figure 2 Morphology of Au NP (a) in hexane under TEM observation and (b) on $\mathrm{TiO}_{2}$ FTO substrate. Uniform 6 nm-diameter Au NP modified by tetraoctylammonium bromide results from the balance between solvent and surfactant. Rough surface of $\mathrm{TiO}_{2}$ on $\mathrm{FTO}$ substrate $(\sim 270 \mathrm{~nm})$ increases the surface area to adsorb chemicals.

We then use a theoretical model to confirm the phenomenon of charge separation and photocurrent formation and the relationship between surface plasmon resonance and photocurrent formation. This result is applicable to improve the intensity of photocurrents in the field of plasmon-sensitized solar cells.

\section{MATERIALS AND METHODS}

Twelve grams of P-25 $\mathrm{TiO}_{2}$ (Degussa, Shinjuku-ku, Japan) powder in $15 \mathrm{ml}$ deionized water mixed with $0.2 \mathrm{ml}$ Triton-X 100 (Sigma, St. Louis, MO, USA) and $0.4 \mathrm{ml}$ acetaldehyde (99.5\%; Fluka, Heidelberg, Germany) were vibrated ultrasonically for 3 days. Subsequently, $0.5 \mathrm{ml}$ $\mathrm{TiO}_{2}$ solution was spin-coated on a fluorine-doped tin oxide (FTO) glass substrate at $1000 \mathrm{rad} \mathrm{s}^{-1}$ for $20 \mathrm{~s}$ and then sintered at $500{ }^{\circ} \mathrm{C}$ for $10 \mathrm{~h}$. After calcinations at $500{ }^{\circ} \mathrm{C}$ for $10 \mathrm{~h}$, the FTO had a sheet resistance of $10.3 \Omega$ per square, and the P-25 had a higher anatase content (rutile/anatase $=1: 4){ }^{15}$

Au nanoparticles (NPs) were synthesized by chemical reduction, by adding $30 \mathrm{ml}$ of $3 \mathrm{mM} \mathrm{HAuCl}_{4(\mathrm{aq})}$ (AlfaAesar, Lancashire, UK) to $80 \mathrm{ml}$ of $5 \mathrm{mM}$ tetraoctylammonium bromide (Sigma) in hexane. To this solution was added $25 \mathrm{ml}$ of $0.05 \mathrm{M} \mathrm{NaBH}_{4 \text { (aq) }}$ (Alfa Aesar).
The color of the solution turned from yellow to black. Au NPs were modified by tetraoctylammonium bromide. The morphology of the $\mathrm{Au}$ NPs in hexane under transmission electron microscopy (TEM) observation and on $\mathrm{TiO}_{2}$ FTO substrate is presented in Figure 2.

Mercapto-propyl-tri-methoxy-silane (95\%; Alfa Aesar) was used as a molecular linker connecting the substrate with the Au NPs through selfassembled monolayers. The $\mathrm{TiO}_{2} / \mathrm{FTO}$ was immersed in the solution $\left(\mathrm{NH}_{4} \mathrm{OH} / \mathrm{H}_{2} \mathrm{O}_{2} / \mathrm{H}_{2} \mathrm{O}=5: 5: 1\right.$ in volume $)$ for $3 \mathrm{~h}$ in order to get modified $\mathrm{OH}^{-}$on the surface of the substrate. The $\mathrm{TiO}_{2} / \mathrm{FTO}$ was then immersed in 1\% 3-mercaptopropyltrimethoxysilane hexane for 1 day, and then in a Au NPs colloid for 1 day. Au NPs were modified on the substrate. Molecular linkers, including 2 wt-\% 2-mercaptoethanol (98\%; Alfa Aesar) and 2 wt-\% 1,3-propanedithiol (97\%; Alfa Aesar) in hexane, were then added to modify the surface of the Au NPs. The Au NPs were immersed with the molecular linkers for 1 day. The sample was immersed in the Au NPs colloid again for 1 day. By repeating the above process five times, layer-by-layer Au NPs were fabricated on the substrate as an anode electrode. Thickness and fraction of layer-by-layer $\mathrm{Au}$ NPs on the $\mathrm{TiO}_{2} /$ FTO substance are presented in Figure 3. Pt was sputtered on the indium-doped tin oxide glass as the cathode electrode.
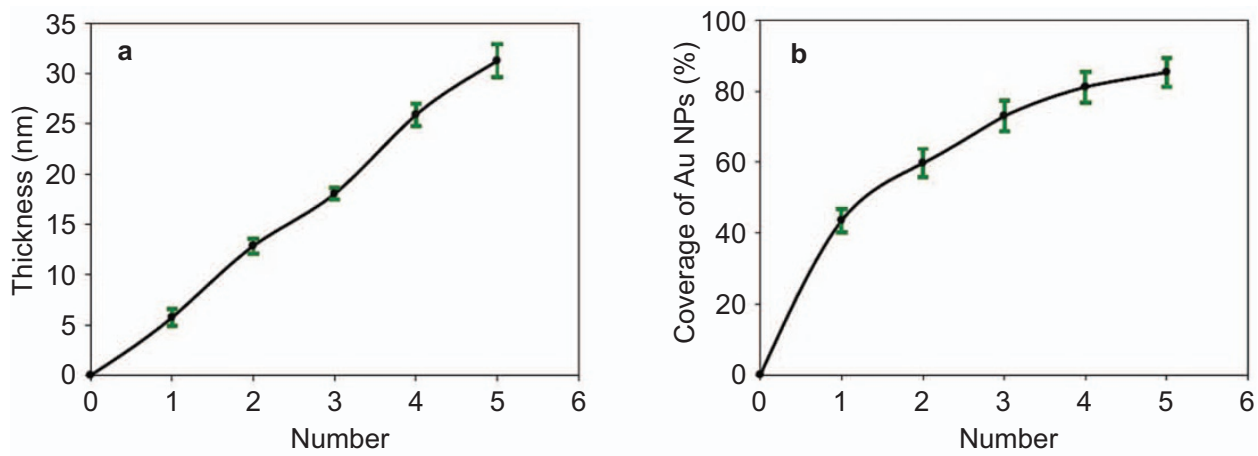

Figure 3 (a) Thickness and (b) fraction of layer-by-layer Au NPs on TiO2/FTO substance. According to the effective medium theory, the relationship between thickness

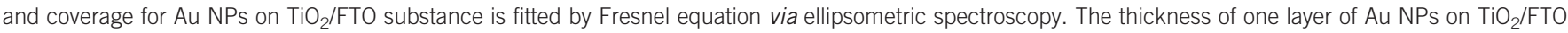

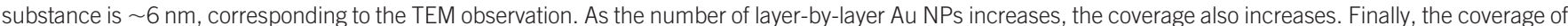
layer-by-layer Au NPs will grow slowly due to the saturation of the reactive surface. 
The electrolyte was a water-based solution (35\% ethanol and $65 \%$ water), including $0.1 \mathrm{M} \mathrm{Ce}\left(\mathrm{NO}_{3}\right)_{3} / 0.05 \mathrm{M} \mathrm{Ce}\left(\mathrm{NO}_{3}\right)_{4}$ (99\%; ICN Biomedicals, Inc., Aurora, OH, USA).

The morphologies of the Au NPs were observed by TEM. The asgrown product was observed by a Hitachi model HF-2000 transmission electron microscope operating at $200 \mathrm{kV}$. The absorption of $\mathrm{Au}$ NPs was observed by UV-visible spectrometry (Hitachi U-2001 spectrophotometer). The sample was directly injected into a quartz tube for UV-visible light analysis. The optical properties and thickness were determined by ellipsometry (h-VASE; Woollam, Lincoln, NE, USA) in the visible light range. The electric properties, current and voltages, were measured by a high voltage Source-Measure unit (Keithley 237). The power of the simulated solar energy (AM1.5) was $100 \mathrm{~mW} \mathrm{~cm}^{-2}$. The J-V curve under solar simulator radiation was recorded.

\section{RESULTS AND DISCUSSION}

\section{Energy level of surface plasmon resonance}

A metal cluster with a diameter greater than $3 \mathrm{~nm}$ has bulk-like physical properties and energy levels that are not discrete. ${ }^{16}$ In our case, the diameter of gold NPs is $\sim 6 \mathrm{~nm}$ as shown in Figure 2a. The Fermi-level of bulk-like gold NPs is the work function. Surface plasmon resonance induces excitons to separate the positive and negative charges. The density of states of the surface plasmon resonance range from 510 to $580 \mathrm{~nm}$ in the visible light region (see also Figure S1 in Supplementary Information). In a solar cell, the Fermi-level of bulk-like gold NPs contacts that of the semiconductor due to the balance of the electronic density on the surface. Energy level, $E$, referred by the expectation value of the surface plasmon resonance's induced dipole, is under the work function of gold NPs. The difference in energy between $E$ and the work function is $E_{g}$, as shown in Figure 1. The SPR of gold NPs induces a dipole, which acts as an energy level to support the transition of photoelectrons. Photoelectrons then transfer from the SPR level of the gold NP to the conduction band of the semiconductor. ${ }^{17}$ Photoelectrons are injected into the anode electrode and are inhibited from returning due to the Schottky barrier. ${ }^{18}$ The charged gold NP is renewed by the donor from the electrolyte, as shown in Figure 1.

\section{SPR enhances photoelectric voltage}

Open-circuit voltage $\left(V_{\text {oc }}\right)$ is determined by the difference between the chemical potential of the electrolyte and the conductive band $(C B)$ of a semiconductor $\left(V_{\mathrm{oc}}=C B-\mu\right)$. For a regular solution case, the Gibbs free energy of an electrolyte is presented as the following:

$$
\mu=X_{\mathrm{Ce}^{4+}}^{2} G_{\mathrm{Ce}^{4+}}+X_{\mathrm{Ce}^{3+}}^{2} G_{\mathrm{Ce}^{3+}}+2 \Omega X_{\mathrm{Ce}^{4+}} X_{\mathrm{Ce}^{3+}}
$$

where $\mu$ is the Gibbs free energy of electrolyte, $X_{\mathrm{Ce}^{4+}}$ is the ratio of $\mathrm{Ce}^{4+}, X_{\mathrm{Ce}^{3+}}$ is the ratio of $\mathrm{Ce}^{3+}, G_{\mathrm{Ce}^{4+}}$ is the Gibbs free energy of $\mathrm{Ce}^{4+}, G_{\mathrm{Ce}^{3+}}$ is the Gibbs free energy of $\mathrm{Ce}^{3+}$, and $\Omega$ is the interaction relationship between $G_{\mathrm{Ce}^{4+}}$ and $G_{\mathrm{Ce}^{3+}}(\Omega$ is constant for a regular solution.). When an external electrical field is applied to the system, the free energy is represented as $G^{\prime}=G-q V$, where $q$ is the charge of the system, $V$ is the potential of the external electrical field and $G$ is the Gibbs free energy. For the $\mathrm{Ce}^{4+}$ system, the free energy is $G_{\mathrm{Ce}^{4+}}{ }^{\prime}=G_{\mathrm{Ce}^{4+}}-(+4 q) V$ due to the four electrons of the system. On the other hand, for the $\mathrm{Ce}^{3+}$ system, the free energy is $G_{\mathrm{Ce}^{3+}}{ }^{\prime}=$ $G_{\mathrm{Ce}^{3+}}-(+3 q) V$, because of the three electrons of the system.

The open-circuit voltage $\left(V_{\mathrm{oc}}\right)$ is represented as the following:

$$
V_{\mathrm{oc}}^{\prime}(V)=V_{\mathrm{oc}}+q\left(4 X_{\mathrm{Ce}^{4+}}^{2}+3 X_{\mathrm{Ce}^{3+}}^{2}\right) V
$$

The open-circuit voltage $\left(V_{\mathrm{oc}}\right)$ is proportional to the external electrical field.

The SPR of gold NPs applies a strong external electric field in the near field. As the number of gold NPs increases, the intensity of SPR rises, as shown in Figure 4. When the array of gold NPs is random, as in Figure 2b, no special peak of SPR appears due to the geometric effect. The open-circuit voltage $\left(V_{\mathrm{oc}}\right)$ is proportional to the external electric field for our experimental results, as shown in Figure $5 c$, corresponding to the above result. SPR produces a stronger electric field that enhances the open-circuit voltage of a photovoltaic cell.

\section{SPR enhances photoelectric current}

The electron excitation process ${ }^{19,20}$ in a photovoltaic cell is shown as follows:

$$
\frac{\mathrm{d} n}{\mathrm{~d} t}=g-\frac{n}{\tau}
$$

where $g$ is the generation, $\tau$ is the lifetime, $\phi_{n}$ is the energy level for electrons and $n$ is the particle number. When processing for a short time interval, $g, \phi_{n}$ and $n$ are represented as follows:
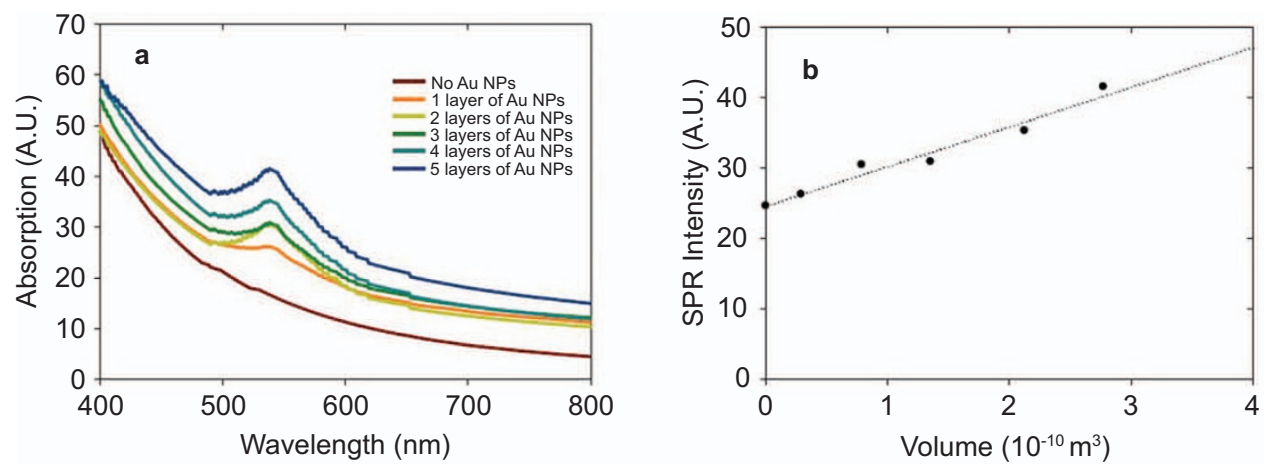

Figure 4 (a) Absorption and (b) relationship between SPR intensity and volume of layer-by-layer Au NPs on TiO $/$ /FTO substrate. SPR peak of layer-by-layer Au NPs on $\mathrm{TiO}_{2} / \mathrm{FTO}$ substance is at $520 \mathrm{~nm}$ from UV-visible spectroscopic observation. SPR intensity is recorded at $520 \mathrm{~nm}$. The count of background contributed by the TiO $/$ FTO substance is 24.6. Volume of layer-by-layer Au NPs is calculated by ellipsometric data, which is multiplied by coverage fraction. The relationship between SPR intensity and volume is a linear one (correlative coefficient is +0.97 ). As the volume of Au NPs increase, the intensity of SPR also increases. The extinction intensity is referred to as the SPR intensity. 

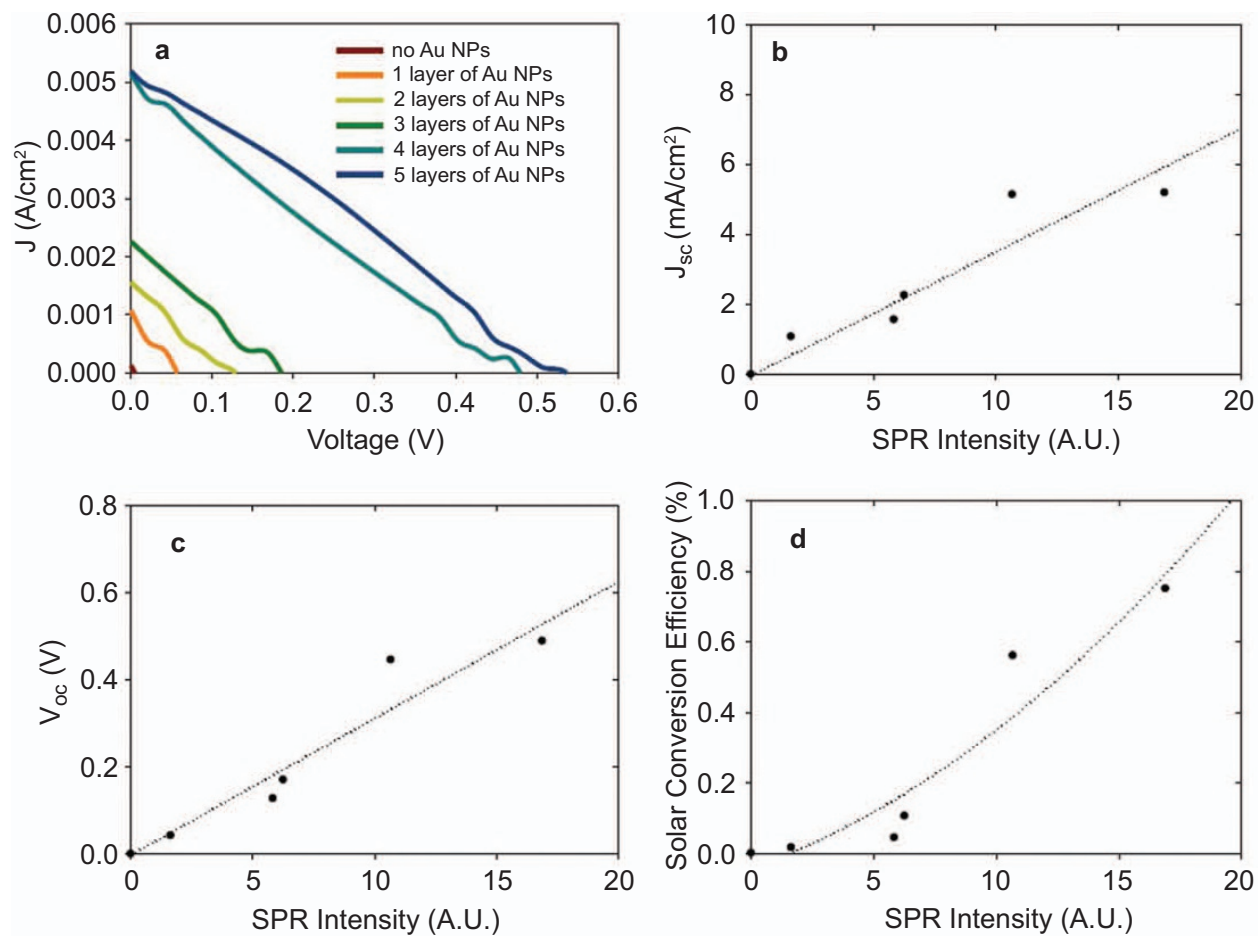

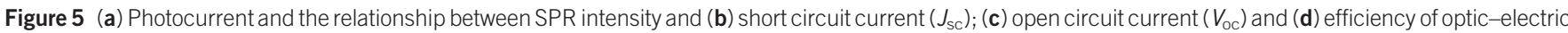
conversion for layer-by-layer Au NPs on $\mathrm{TiO}_{2} / \mathrm{FTO}$ substance under the solar simulator (AM1.5) illumination. Relationships between SPR intensity and short circuit

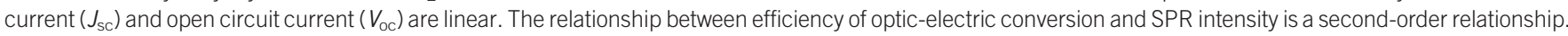
The correlative coefficient between SPR intensity and short circuit current $\left(J_{\mathrm{Sc}}\right)$, open circuit current $\left(V_{\text {oc }}\right)$, and efficiency are $+0.94,+0.96$ and +0.95 , respectively. The background of SPR intensity is removed.

$$
\left\{\begin{array}{l}
n \Rightarrow n+\rho_{n}(t) \\
\phi_{n} \Rightarrow \phi_{n}+\phi_{n}(t) \\
g \Rightarrow g
\end{array}\right.
$$

Then this can be applied in the electron excitation process:

$$
\frac{\mathrm{d} \rho_{n}}{\mathrm{~d} t}=g-\frac{\rho_{n}}{\tau}
$$

And $n=n_{0} e^{\left(E_{\mathrm{f}}-E_{0}\right) / k_{B} T}$ and $E_{\mathrm{f}}-E_{0}=-e \phi_{n} \Rightarrow \rho_{n}=-\frac{e n}{k_{B} T} \phi_{n}$. Then

$$
\frac{e^{2} n}{k_{B} T} \frac{\mathrm{d} \phi_{n}}{\mathrm{~d} t}+e g+\frac{e^{2} n}{\tau k_{B} T} \phi_{n}=0
$$

In the above equation, the chemical effective capacity is $C_{\mu}=$ $C_{\mathrm{ch}}=\frac{e^{2} n}{k_{B} T}$, the physical effective current is $i_{\mathrm{ph}}=e g$, and the reaction effective resistance is $R_{\mathrm{rec}}=\left(\frac{e^{2} n}{\tau k_{B} T}\right)^{-1}$. In the above equation, the term, $e g$, is the special solution for the effective current: $J \propto-e g$.

SPR can produce a strong electric field that functions as the hot spot to enhance the pumping rate of the electrons between bands. During this process, the generation, $g$, will increase. As the generation increases, the effective current in a photovoltaic cell will rise. The short-circuit current will rise at the same time. In our experiment, the short-circuit current is proportional to the SPR intensity, as is shown in Figure 5b, which presents the relation: $J_{\mathrm{sc}}(V) \propto-e g \propto V$.

\section{SPR enhances photoelectric properties}

In a photovoltaic cell, the current-voltage curve of a solar cell yields important operational parameters, ${ }^{21}$ among which are the short-circuit current $J_{\mathrm{sc}}$, the open-circuit voltage $V_{\mathrm{oc}}$, the current $J_{\mathrm{mp}}$ and voltage $V_{\mathrm{mp}}$ at the maximum power point $P_{\max }$. The fill factor $(F F)$ is defined as

$$
F F=\frac{P_{\max }}{V_{\mathrm{oc}} J_{\mathrm{sc}}}=\frac{V_{\mathrm{mp}} J_{\mathrm{mp}}}{V_{\mathrm{oc}} J_{\mathrm{sc}}}
$$

The solar conversion efficiency $(\eta)$ is given by

$$
\eta=\frac{P_{\mathrm{max}}}{P_{\mathrm{s}}}=\frac{F F V_{\mathrm{oc}} J_{\mathrm{sc}}}{P_{\mathrm{s}}}=\frac{V_{\mathrm{mp}} J_{\mathrm{mp}}}{P_{\mathrm{s}}}
$$

where $P_{\mathrm{s}}$ is the input solar irradiance (in $\mathrm{mW} \mathrm{cm}^{-2}$ ).

In a $\mathrm{p}-\mathrm{n}$ junction solar cell model, ${ }^{22}$ the $V_{\mathrm{mp}}, J_{\mathrm{mp}}$ and $F F$ can be determined as:

$$
\begin{aligned}
& V_{\mathrm{mp}}=V_{\mathrm{oc}}-\frac{k_{B} T}{e} \ln \left(1+\frac{e V_{\mathrm{oc}}}{k_{B} T}\right) \\
& J_{\mathrm{mp}}=J_{\mathrm{s}}\left[\exp \left(\frac{e V_{\mathrm{mp}}}{k_{B} T}-1\right)+J_{\mathrm{sc}}\right]
\end{aligned}
$$

where $J_{\mathrm{s}}$ is the saturated current in a photovoltaic cell, and

$$
F F=\frac{e V_{\mathrm{oc}} / k_{B} T-\ln \left(1+e V_{\mathrm{oc}} / k_{B} T\right)}{1+e V_{\mathrm{oc}} / k_{B} T}
$$

When SPR is applied in a solar cell, $V_{\mathrm{oc}}{ }^{\prime}=V_{\mathrm{oc}}+q\left(4 X_{\mathrm{Ce}^{4+}}^{2}+\right.$ $\left.3 X_{\mathrm{Ce}^{3+}}^{2}\right) V$ and $J_{\mathrm{sc}} \propto V$ are put into the above equations, then $V_{\mathrm{mp}}{ }^{\prime}$, $J_{\mathrm{mp}}{ }^{\prime}$ and $F F^{\prime}$ are represented in the SPR solar cell case as:

$$
F F^{\prime}(V)=\frac{(b-1)+a V / k_{B} T-\ln \left(b+a V / k_{B} T\right)}{b+a V / k_{B} T}
$$


Table 1 Photoelectric characteristic of layer-by-layer Au NPs

\begin{tabular}{llccl}
\hline & $V_{\text {oc }}(\mathrm{V})$ & $J_{\mathrm{sc}}\left(\mathrm{mA} \mathrm{cm}^{-2}\right)$ & $F F(\%)$ & $\eta(\%)$ \\
\hline 1 layer of Au NPs & 0.042 & 1.076 & 35.045 & 0.016 \\
2 layers of Au NPs & 0.127 & 1.562 & 22.266 & 0.044 \\
3 layers of Au NPs & 0.17 & 2.260 & 27.503 & 0.105 \\
4 layers of Au NPs & 0.445 & 5.140 & 24.482 & 0.560 \\
5 layers of Au NPs & 0.488 & 5.192 & 29.620 & 0.750 \\
\hline
\end{tabular}

$V_{\text {oc }}$, voltage of open circuit; $J_{\mathrm{sc}}$, electric current of short circuit; $F F$, filling factor; $\eta$, efficiency of photoelectric conversion; Au NPs, gold nanoparticles.

where $b=1+e V_{\mathrm{oc}} / k_{B} T$ and $a=e q\left(4 X_{\mathrm{Ce}^{4+}}^{2}+3 X_{\mathrm{Ce}^{3+}}^{2}\right) .(b-1)+a V /$ $k_{B} T$ and $-\ln \left(b+a V / k_{B} T\right)$ act as the antagonism for the $F F^{\prime}$, which makes the relationship between SPR intensity and the fill factor irregular, as shown in Table 1 . The solar conversion efficiency $\left(\eta^{\prime}\right)$ is given by

$\eta^{\prime}(V)=\frac{P_{\max }}{P_{\mathrm{s}}}=\frac{V_{\mathrm{mp}} J_{\mathrm{mp}}}{P_{\mathrm{s}}}=\frac{\left(V_{\mathrm{mp}}+\frac{a}{e} V\right)\left[\frac{J_{\mathrm{mp}}}{J_{\mathrm{s}}}+J_{\mathrm{sc}}{ }^{\prime}\left(1-\frac{\exp (0)}{J_{\mathrm{s}}}\right)\right]}{P_{\mathrm{s}}}$

The solar conversion efficiency $\left(\eta^{\prime}\right)$ is a second-order equation of the external electric SPR field. In our experiment, the solar conversion efficiency $\left(\eta^{\prime}\right)$ is a second-order equation of SPR intensity, as shown in Figure 5d.

By modeling the phenomenon of photoelectric conversion efficiency induced by SPR, the mechanism of solar conversion efficiency can be better understood, which could be used to enhance the efficiency of plasmon-sensitized solar cells in the future.

\section{CONCLUSION}

Gold nanoaprticles separate charges under visible light radiation. We fabricated gold nanoparticles using the layer-by-layer method on a $\mathrm{TiO}_{2}$ film to form multilayers in order to increase the intensity of the photocurrent. The efficiency of photoelectric conversion increased as the thickness increased. After optimization, nobel metal nanoparticles are possible candidates to replace dyes in solar cells and to act as plasmon-sensitized solar cells and plasmonic solar cells in the future.
2 Kabashin AV, Evans P, Pastkovsky S, Hendren W, Wurtz GA et al. Plasmonic nanorod metamaterials for biosensing, Plasmonic-metal nanostructures for efficient conversion of solar to chemical energy. Nat Mater 2009; 8: 867-871.

3 Li HB, Li FY, Han CP, Cui ZM, Xie GY et al. Highly sensitive and selective tryptophan colorimetric sensor based on 4,4-bipyridine-functionalized silver nanoparticles. Sens Actuat B Chem. 2009; 145: 194.

4 Tian Y, Shi X, Lu CQ, Wang SL. Charge separation in solid-state gold nanoparticlessensitized photovoltaic cell. Electrochem Commun 2009; 11: 1603-1605.

5 Cuevas-Muniz FM, Guerra-Balcazar M, Castaneda F, Ledesma-Garcia J, Arriaga LG. Performance of Au and AuAg nanoparticles supported on Vulcan in a glucose laminar membraneless microfuel cell. J Power Sources 2011; 196: 5853.

6 Lu YZ, Wang YC, Chen W. Silver nanorods for oxygen reduction: Strong effects of protecting ligand on the electrocatalytic activity. J Power Sources 2011; 196: 3033.

7 Zhou HQ, Qu CY, Yu F, Yang HC, Chen MJ et al. Thickness-dependent morphologies and surface-enhanced raman scattering of Ag deposited on n-Layer graphenes. J Phys Chem C 2011; 115: 11348-11354.

8 Niu BJ, Wu LL, Tang W, Zhang XT, Meng QG. Enhancement of near-band edge emission of $\mathrm{Au} / \mathrm{ZnO}$ composite nanobelts by surface plasmon resonance. CryStengComm 2011; 13: 3678-3681.

9 Su YH, Tu SL, Tseng SW, Chang YC, Chang SH et al. Influence of surface plasmon resonance on the emission intermittency of photoluminescence from gold nano-seaurchins. Nanoscale 2010; 2: 2639-2646.

10 Baba A, Aoki N, Shinbo K, Kato K, Kaneko F. Grating-coupled surface plasmon enhanced short-circuit current in organic thin-film photovoltaic cells. ACS Appl Mater Interf 2011; 3: 2080-2084.

11 Furube A, Du L, Hara K, Katoh R, Tachiya M. Ultrafast plasmon-induced electron transfer from gold nanodots into $\mathrm{TiO}_{2}$ nanoparticles. J Am Chem Soc 2007; 129: 14852.

12 Linic S, Christopher P, Ingram DB. Plasmonic-metal nanostructures for efficient conversion of solar to chemical energy. Nat Mater 2011; 10: 911.

13 Tian Y, Tatsuma T. Plasmon-induced photoelectrochemistry at metal nanoparticles supported on nanoporous $\mathrm{TiO}_{2}$. Chem Commun (Camb) 2004; (16): 1810-1811

14 Tian Y, Tatsuma T. Mechanisms and applications of plasmon-induced charge separation at $\mathrm{TiO}_{2}$ films loaded with gold nanoparticles. J Am Chem Soc 2005; 127: 7632.

15 Two highly dispersed metallic oxides by the aerosil process. Degussa Corp.: Akron, $\mathrm{OH}$ USA, 1990. Degussa technical bulletin no. 56

16 Zhu M, Aikens CM, Hollander FJ, Schatz GC, Jin R. Correlating the crystal structure of a thiol-protected $\mathrm{Au}_{25}$ cluster and optical properties. J Am Chem Soc 2008; 130: 5883.

17 Furube A, Du L, Hara K, Katoh R, Tachiya M. Ultrafast plasmon-induced electron transfer from gold nanodots into $\mathrm{TiO}_{2}$ nanoparticles. J Am Chem Soc 2007; 129: 14852.

18 McFarland EW, Tang J. A photovoltaic device structure based on internal electron emission. Nature 2003; 421: 616.

19 Bisquert J, Cahen D, Hodes G, Riihle S, Zaban A. Physical chemical principles of photovoltaic conversion with nanoparticulate, mesoporous dye-sensitized solar cells. J Phys Chem B 2004; 108: 8106.

20 Wang Q, Ito S, Gratzel M, Fabregat-Santiago F, Mora-Seró I et al. Characteristics of high efficiency dye-sensitized solar cells. J Phys Chem B 2006; 110: 25210.

21 Smestad GP. Optoelectronics of solar cells. Washington, DC: SPIE; 2002.

22 Wurfel P. Physics of Solar Cells: From Principles to New Concepts. Weinhein: WileyVCH Verlag GmbH \& Co. KGaA; 2005.

\section{ACKNOWLEDGMENTS}

This work was financially supported by the National Science Council of

Taiwan, No. 100-2218-E-259-003-MY3, which is gratefully acknowledged.

1 Huang XQ, Tang SH, Mu XL, Dai Y, Chen GX et al. Freestanding palladium nanosheets with plasmonic and catalytic properties. Nat Nanotechnol 2011; 6: 28-32.

(c)

This work is licensed under a Creative Commons Attribution-NonCommercial-NoDerivative Works 3.0 Unported License. To view a copy of this license, visit http:// creativecommons.org/licenses/by-nc-nd/3.0 